\title{
EARLY INSURE THERAPY REDUCES CPAP FAILURE IN LATE PRETERM NEWBORNS WITH RESPIRATORY DISTRESS SYNDROME
}

Alarcón-Olave MC ${ }^{1}$, Gómez-Ochoa SA ${ }^{1}$, Jerez-Torra KA ${ }^{1}$, Martínez-González $\mathrm{P}^{1}$, Sarmiento-Villamizar $\mathrm{D}^{1}$, Díaz-Martínez LA ${ }^{1}, \mathrm{Africano-}$ León $\mathrm{ML}^{1,2,3}$, Rojas-Devia MA ${ }^{1,4}$, Pérez-Vera LA ${ }^{1,2}$.

1. School of Medicine, Health Faculty, Universidad Industrial de Santander, Bucaramanga, Colombia; 2. Hospital Universitario de Santander, Bucaramanga, Colombia; 3. Clínica Materno Infantil San Luis, Bucaramanga, Colombia. 4, Department of Pediatrics, Division of Neonatology, Valley Children's Hospital, Madera, California, United States of America.

Background and aims: INSURE (Intubation, Surfactant administration and Extubation) therapy supplement the deficiency of pulmonary surfactant present in RDS in extreme preterm newborns. Nevertheless, late preterm newborns are also in risk and its treatment is still controversial. The aim of this study is to evaluate if INSURE therapy shows an additional benefit over the use of only CPAP regarding CPAP failure and other secondary outcomes $(1,2)$.

Methods: Retrospective cohort study performed at two neonatal care units in Bucaramanga, Colombia. Newborns born with gestational age between 34-366/7 weeks during 2013-2016, that developed early RDS and were treated with CPAP were included. Information about relevant demographic and clinical conditions was collected. CPAP failure incidence was estimated in CPAP only and INSURE patients, its association was measured by a binomial regression. The study was approved by respective Institutional Review Boards.

Table 1. Significant Differences Among the Baseline Characteristics of the Included Newborns and their Mothers According to the Treatment Strategy

\begin{tabular}{|l|c|c|c|}
\hline \multicolumn{1}{|c|}{ Variables } & CPAP (n=57) & INSURE (n=151) & p-value \\
\hline HUS & $3(5.26 \%)$ & $107(70.86 \%)$ & $<0.001$ \\
CMISL & $54(94.74 \%)$ & $44(29.14 \%)$ & \\
\hline IUGR & $4(7.02 \%)$ & $29(19.21 \%)$ & 0.032 \\
\hline SA Score & & & \\
\hline $\begin{array}{l}\mathbf{1} \text { to 3 points } \\
\mathbf{4} \text { to } \mathbf{6} \text { points }\end{array}$ & $12(21.05 \%)$ & $4(2.78 \%)$ & $<0.001$ \\
\hline $\begin{array}{l}\mathbf{7} \text { to 10 points } \\
\text { Not registered }\end{array}$ & $12(20.05 \%)$ & $67(46.53 \%)$ & 0.357 \\
\hline $\begin{array}{l}\text { Starting PEEP (cm } \\
\text { H }\end{array}$ & - & $7(4.64 \%)$ & 0.011 \\
\hline
\end{tabular}

Results: 208 patients were included (57 in CPAP and rescue surfactant and $151 \mathrm{CPAP}+$ INSURE). Early INSURE was reported in 117 patients (56.3\%). INSURE therapy was associated with a reduced risk of CPAP failure $(\mathrm{RR}=0.50 ; 95 \% \mathrm{Cl} 0.26-0.98)$, however, this effect was evident only when surfactant was administered within the first two hours of life $(\mathrm{RR}=0.29 ; 95 \% \mathrm{Cl} 0.12-0.69)$.
Early INSURE was also associated with a decreased risk of pneumothorax $(\mathrm{RR}=0.07 ; 95 \% \mathrm{Cl} 0.01-0.77)$ and pulmonary hypertension (RR=0.34; 95\% Cl 0.14-0.78).

Table 2. Outcomes of the RDS According to the Treatment Strategy

\begin{tabular}{|l|c|c|c|}
\hline \multicolumn{1}{|c|}{ Characteristic } & $\begin{array}{c}\text { CPAP } \\
(\mathbf{n = 5 7 )}\end{array}$ & INSURE (n=151) & p-value \\
\hline $\begin{array}{l}\text { Primary outcome } \\
\text { CPAP failure }\end{array}$ & $15(26.3 \%)$ & $18(11.9 \%)$ & $\mathbf{0 . 0 1 1}$ \\
Secondary outcomes & $1(1.75 \%)$ & $1(0.66 \%)$ & 0.593 \\
Necrotizing enterocolitis & $6(10.53 \%)$ & $5(3.31 \%)$ & $\mathbf{0 . 0 3 8}$ \\
Pneumothorax & $1(1.75 \%)$ & - & 0.202 \\
BPD & $12(21.05 \%)$ & $14(9.27 \%)$ & $\mathbf{0 . 0 2 0}$ \\
Pulmonary hypertension & $6(10.5 \%)$ & $7(4.63 \%)$ & \\
$\quad$ Mild & $2(3.5 \%)$ & $4(2.64 \%)$ & \\
$\quad \begin{array}{l}\text { Moderate } \\
\text { Severe }\end{array}$ & $4(7.05 \%)$ & $3(1.98 \%)$ & \\
\hline
\end{tabular}

Figure 1. Time to CPAP failure by treatment group, including early or late INSURE treatment.

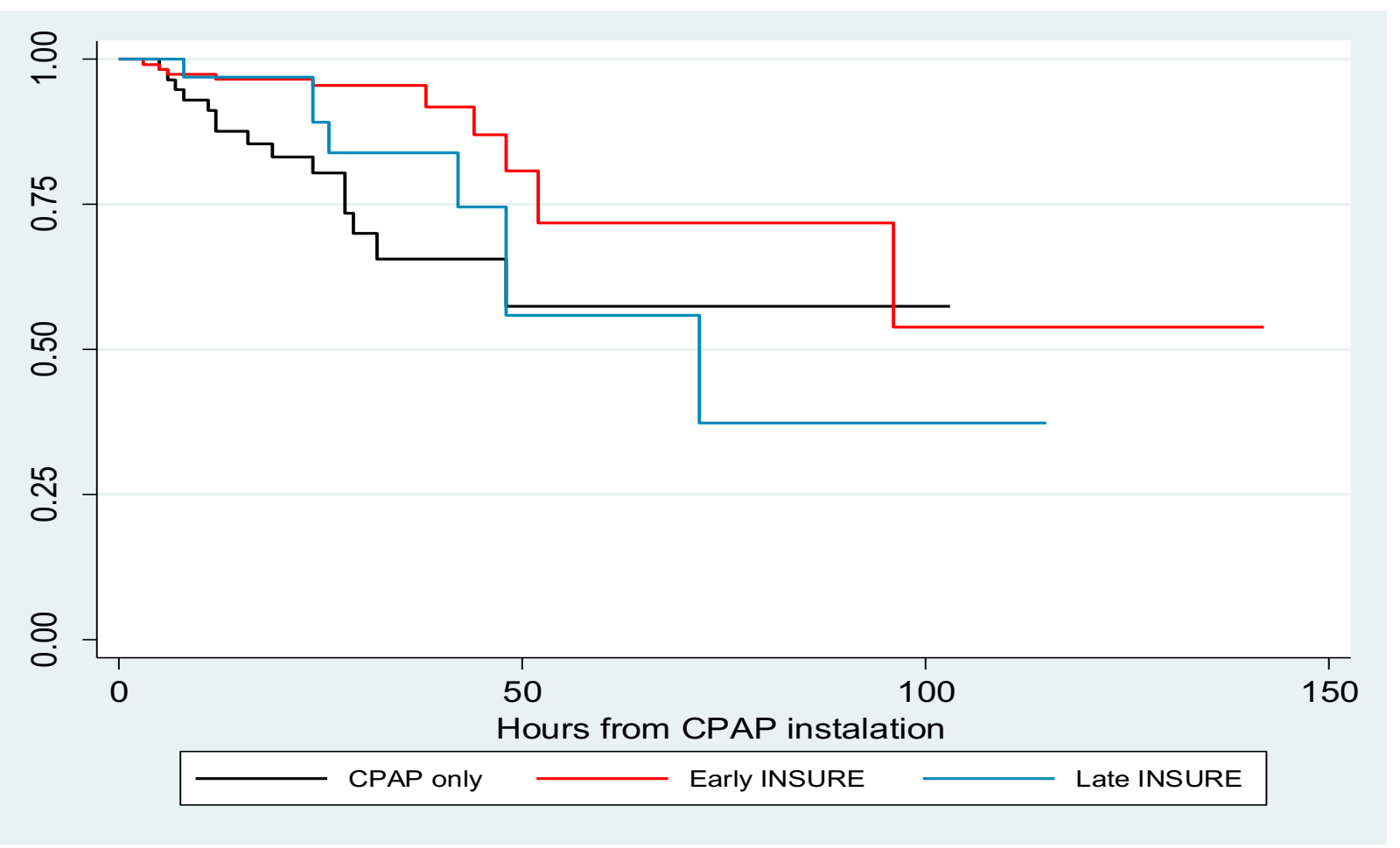

Conclusions: The early application of surfactant therapy showed a beneficial effect in RDS syndrome in this population, however, a late application should be avoided, as was correlated to an increased risk of CPAP failure.

\section{References:}

1.) Sankar MJ, Gupta N, Jain K, Agarwal R, Paul VK. Efficacy and safety of surfactant replacement therapy for preterm neonates with respiratory distress syndrome in low- and middle-income countries: a systematic review. J Perinatol. 2016;36 Suppl 1:S36-48.

2.) Sardesai $S$, Biniwale $M$, Wertheimer $F$, Garingo $A$, Ramanathan $R$ Evolution of surfactant therapy for respiratory distress syndrome: past, present, and future. Pediatr Res. 2017;81(1-2):240-248 